\title{
Clinical Study \\ Breast Cancer Treatment Practices in Elderly Women in a Community Hospital
}

\author{
Hua Wang, Awinder P. Singh, Serena A. St. Luce, and Alan R. Go \\ Department of Surgery, The Brooklyn Hospital Center, 121 Dekalb Avenue, Brooklyn, NY 11201, USA \\ Correspondence should be addressed to Alan R. Go, arg9003@nyp.org
}

Received 10 May 2011; Accepted 20 September 2011

Academic Editor: Owen A. Ung

Copyright (๑) 2011 Hua Wang et al. This is an open access article distributed under the Creative Commons Attribution License, which permits unrestricted use, distribution, and reproduction in any medium, provided the original work is properly cited.

\begin{abstract}
Background. Elderly women with breast cancer are considered underdiagnosed and undertreated, and this adversely affects their overall survival. Methods. A total of 393 female breast cancer patients aged 70 years and older, diagnosed within the years $1989-$ 1999, were identified from the tumor registry of The Brooklyn Hospital Center. Comparisons between the 3 different subgroups $70-74,75-79$, and 80 years and older were made using the Pearson Chi Square test. Results. Lumpectomy was performed in $42 \%$ of all patients, while mastectomy was done in $46 \%$ of patients. Adjuvant therapy such as chemotherapy, radiation therapy, and hormonal therapy were done in $12 \%, 25 \%$, and $38 \%$, respectively. Forty-seven percent of patients with positive lymph nodes received chemotherapy. Eighty-six percent of patients who were estrogen receptor-positive received adjuvant hormonal therapy. Overall five-year survival was only $14 \%$ for the $\geq 80$ age group, compared to that of $32 \%$ and $35 \%$ for the $70-74$ and the $75-79$ age groups, respectively. Conclusions. Surgery was performed in majority of these patients, about half received lumpectomy, the other half mastectomy. Adjuvant therapies were frequently excluded, with only hormonal therapy being the most commonly used. Overall five-year survival is significantly worse in patients $\geq 80$ years with breast cancer.
\end{abstract}

\section{Introduction}

Breast cancer is still the most common cause of death for women in the United States. Interestingly, we see that as the population ages, we likewise see an increase in the number of patients diagnosed with breast cancer. Increasing age remains the greatest risk factor in developing the disease. It is estimated that by $2030,20 \%$ of Americans will be over the age of 65 . Studies have shown that around $50 \%$ of patients with breast cancer are those older than 65 years of age and that approximately $35 \%$ are older than 70 years $[1,2]$. Most women who die of breast cancer are over the age of 65 $[3,4]$. Yet despite this information, it is observed in a number of studies that elderly patients do not receive the standard treatment when compared to their younger counterparts $[5,6]$. And at the heart of this dilemma is that as patients advance in age, the incidence of cancer increases, but so does significant medical comorbidities. And it is the latter that may significantly affect treatment options in most patients. However, a number of studies have cited that age alone was a determining factor in the type of treatment a patient with breast cancer would receive $[7,8]$.
Studies collectively show that older patients with breast cancer are more likely to be undertreated compared to younger patients $[9,10]$. To date, there is no consensus as to what the best treatment is for older patients [9]. Part of it is because older breast cancer patients are not very well represented in clinical trials [11]. There are also suggestions that treatment should include consideration of nonbreastcancer-specific survival, functional status, and patient and family preference (goals of care). In terms of life expectancy, data from the National Vital Statistics Reports from the Centers for Disease Control and Prevention (CDC) released in 2003 have shown that females at age 70 have an average life expectancy of 15 years if they are relatively healthy and 7 years for those over 85 years old [12]. The care for an elderly breast cancer patient is indeed very complicated. Thus, treatment of an elderly patient should be multidisciplinary, possibly requiring the expertise of a primary care physician, a geriatrician, a psychiatrist, a surgeon, and a medical and radiation oncologist.

Screening is likewise very controversial in the elderly population. There are very few retrospective and prospective 
studies looking specifically at cancer screening in the elderly. The US Preventive Services Task Force (USPSTF) recommends screening mammography, with or without clinical breast examination (CBE), every 1-2 years for women aged 40 and older [13]. Despite this, however, mammography was noted to be used $72 \%$ as adjunct to clinical examination in these older women and only around $30 \%-38 \%$ in women over 80 with occult disease [14]. These suggest that mammography was not largely used for screening purposes in the elderly patient with breast cancer [14].

Knowing that around $77 \%$ of deaths attributed to breast cancer are in women older than 55 years of age, it is truly interesting to note that there is an observed age-related difference in treatment and screening for breast cancer. The study intend to determine whether treatment of and screening for breast cancer in the elderly in a community hospital is appropriate. Improved treatment of older patients with breast cancer is of paramount importance if we are to properly address the growing number of cases and deaths due to breast cancer.

\section{Methods}

The investigators identified the patients in the study using the American College of Surgeons Committee on Canceraccredited tumor registry database of The Brooklyn Hospital Center. Patients between the years 1989-1999 were included in the study if they were older than 70 years old at the time of breast cancer diagnosis. The patients were then subsequently divided into three age subgroups: 70-74, 7579 , and $\geq 80$, roughly corresponding to the age categories used in the geriatric population - the young old (often 65-74 years), the middle old (75-85 years), and the very oldest old ( $\geq 95$ years). The following information for each subgroup were gathered from the registry: size, grade, histologic type of tumor, complete staging, estrogen receptor status, type of surgical procedure done, type of adjuvant therapy given, and survival data 5 years after diagnosis. The Pearson Chisquare test was used to compare patient characteristics and types of treatment between patient groups. A $P$ value of 0.05 was designated as being significant. The protocol was approved by The Brooklyn Hospital Center's Institutional Review Board (IRB).

\section{Results}

There were a total of 393 female patients (age over 70 years) treated for breast cancer at the Brooklyn Hospital center between January 1989 and December 1999 that were divided into 3 different subgroups. There were 151 patients (38\%) in the 70-74 years old group, 101 patients (27\%) in the 75-79 years old groups, and 141 patients $(36 \%)$ in the $>80$ years old group. Majority of our patient population was non-Hispanic blacks in all age groups $(63 \%, 65 \%$, and $52 \%)$, followed by Hispanics $(26 \%)$, then white non-Hispanic (11\%) and Asians (3\%). The characteristics of the patients identified through the tumor registry are outlined in Table 1. Information on whether the patients presented with a palpable breast mass or were diagnosed based on mammography, as well as information on the patients' functional status and comorbidities were not available in the tumor registry database. There was no significant difference in the tumor size for all age groups (median size was $3.0 \mathrm{~cm}$ ). Only $7 \%$ of all patients have a tumor size of $<1.0 \mathrm{~cm}$ (nonpalpable). Thirty-nine percent of patients diagnosed were designated as having Stage II disease. Stage IV disease accounted for 3\% of total cases. Ductal carcinoma was still the most common histologic type demonstrated in all age groups $(69 \%, 67 \%$, and $62 \%$ ). Tumor grade was not identified in roughly half $(43 \%)$ of these patients. Of those with tumor grading, moderately differentiated tumors were found to be most predominant. Complete staging was done in $71 \%$ of patients. It was noted to be omitted more in women older than 80 , but was not statistically significant $(P \leq 0.20)$. About forty-three percent of tumors expressed estrogen receptors. However, about $46 \%$ of tumors had unknown estrogen receptor status. Similarly, only $36 \%$ of tumors had known positive progesterone status and was unknown in $46 \%$. Surgery was not performed in about $11 \%$ of the patients $(P \leq 1)$. Breast conservation surgery (lumpectomy) was performed in about $42 \%$ of all patients, while mastectomy was done in $46 \%$ of patients. Of the patients who did not undergo surgery, it was not indicated in the tumor registry database as to whether they were not candidates or whether the patients had refused the procedure. Adjuvant therapy such as chemotherapy, radiation therapy, and hormonal therapy were done in $12 \%, 25 \%$, and $38 \%$, respectively. The use of chemotherapy was noted to have no significant difference in the three age groups. The same observation was noted for radiation and hormonal therapy with $P$ values of $\leq 0.10$ and $\leq 1$, respectively. However, survival data after five years of diagnosis showed significant difference between the $75-79$ and $\geq 80$ age groups $(P \leq 0.001)$ as well as that of the $70-74$ and the $\geq 80$ age groups $(P \leq 0.001)$. Overall five-year survival was only $14 \%$ for the $\geq 80$ age group, compared to that of $32 \%$ and $35 \%$ for the $70-74$ and the $75-79$ age groups, respectively. No significant difference was noted between the $70-74$ and the 75-79 age groups in terms of five-year survival $(P \leq 1)$.

The type of therapy, if any, in addition to either mastectomy or lumpectomy was likewise analyzed from the tumor registry database and presented in Table 2. For patients who underwent mastectomy, there was note of a trend to offer adjuvant treatment to the younger cohort $(70-74$ versus $\geq 80$ years old). However, the difference was not statistically significant $(P \leq 0.20)$. Chemotherapy and radiation therapy were given more to younger patients. That of hormonal therapy was noted to be the same. For those patients who underwent lumpectomy, the opposite trend was observed. Patients who were older were given more adjuvant treatment than the younger age group although again, the difference did not have statistical significance. Of note is that there were no patients given chemotherapy in those who had lumpectomy in the 70-74 age group, whereas about $20 \%$ received such therapy in the 80 and older group $(P \leq 0.01)$.

The results in Table 3 showed that $47 \%$ of patients found to have positive lymph nodes received some form of 
Table 1: Patient characteristics (1989-1999).

\begin{tabular}{|c|c|c|c|c|c|}
\hline \multirow{2}{*}{ Characteristic } & \multicolumn{3}{|c|}{ Age } & \multirow{2}{*}{ Total } & \multirow{2}{*}{$P$ value } \\
\hline & $70-74$ & $75-79$ & $\geq 80$ & & \\
\hline Patients, number (\%) & $151(38)$ & $101(27)$ & $141(36)$ & $393(100)$ & NA \\
\hline \multicolumn{6}{|l|}{ Race, number (\%) } \\
\hline Black, non-Hispanic & $95(63)$ & $66(65)$ & $73(52)$ & $234(59)$ & \multirow{4}{*}{$\begin{array}{l}P \leq 0.001 \\
\quad \mathrm{~S}\end{array}$} \\
\hline Asian & $0(0)$ & $5(5)$ & $7(5)$ & $12(3)$ & \\
\hline White, non-Hispanic & $39(26)$ & $2(2)$ & $2(1)$ & $43(11)$ & \\
\hline Hispanic & $17(12)$ & $28(28)$ & $59(42)$ & $104(26)$ & \\
\hline $\begin{array}{l}\text { Size of tumor, median } \pm \text { standard } \\
\text { deviation, } \mathrm{cm}\end{array}$ & $3.0 \pm 2.7$ & $2.5 \pm 2.0$ & $3.0 \pm 1.96$ & $\mathrm{NA}$ & NA \\
\hline \multicolumn{6}{|l|}{ Size of tumor, number (\%) } \\
\hline <1 cm (nonpalpable) & $8(5)$ & $7(7)$ & $12(9)$ & $27(7)$ & \multirow{3}{*}{ NA } \\
\hline$\geq 1 \mathrm{~cm}$ (palpable) & $126(84)$ & $82(80)$ & $113(80)$ & $321(82)$ & \\
\hline Unknown & $16(11)$ & $13(13)$ & $16(11)$ & $45(11)$ & \\
\hline \multicolumn{6}{|l|}{ Stage, number $(\%)$} \\
\hline 0 & 10 & 13 & 7 & $30(8)$ & \multirow{6}{*}{$\begin{array}{l}P \leq 0.20 \\
\text { NS }\end{array}$} \\
\hline 1 & 38 & 22 & 33 & $93(24)$ & \\
\hline 2 & 59 & 39 & 54 & $152(39)$ & \\
\hline 3 & 23 & 9 & 24 & $56(14)$ & \\
\hline 4 & 20 & 16 & 24 & $60(15)$ & \\
\hline Unknown & 1 & 2 & 8 & $11(3)$ & \\
\hline \multicolumn{6}{|l|}{ Histologic type, number (\%) } \\
\hline Ductal & $104(69)$ & $68(67)$ & $88(62)$ & $260(66)$ & \multirow{4}{*}{$\begin{array}{l}P \leq 1 \\
\text { NS }\end{array}$} \\
\hline Lobular & $4(3)$ & $4(4)$ & $10(7)$ & $18(4)$ & \\
\hline Papillary & $2(1)$ & $1(1)$ & $1(1)$ & $4(1)$ & \\
\hline Other & $41(27)$ & $28(28)$ & $42(30)$ & $111(28)$ & \\
\hline \multicolumn{6}{|l|}{ Grade, number (\%) } \\
\hline 1 (well differentiated) & $7(5)$ & $6(6)$ & $6(4)$ & $19(5)$ & \multirow{4}{*}{$\begin{array}{l}P \leq 1 \\
\text { NS }\end{array}$} \\
\hline 2 (moderately differentiated) & $48(32)$ & $26(26)$ & $52(37)$ & $126(32)$ & \\
\hline 3 (poorly differentiated) & $24(16)$ & $13(13)$ & $20(14)$ & $57(14)$ & \\
\hline Unknown & $72(48)$ & $55(54)$ & $63(45)$ & $190(43)$ & \\
\hline \multicolumn{6}{|l|}{ Estrogen receptor, number (\%) } \\
\hline Positive & $69(46)$ & $44(44)$ & $58(41)$ & $171(43)$ & \multirow{3}{*}{$\begin{array}{l}P \leq 0.20 \\
\text { NS }\end{array}$} \\
\hline Negative & $14(9)$ & $21(21)$ & $13(9)$ & $48(12)$ & \\
\hline Unknown & $68(45)$ & $48(47)$ & $70(50)$ & $186(47)$ & \\
\hline \multicolumn{6}{|l|}{ Progesterone receptor, number (\%) } \\
\hline Positive & $63(42)$ & $32(32)$ & $45(32)$ & $140(36)$ & \multirow{3}{*}{$\begin{array}{l}P \leq 1 \\
\text { NS }\end{array}$} \\
\hline Negative & $24(16)$ & $21(21)$ & $26(18)$ & $71(18)$ & \\
\hline Unknown & $64(42)$ & $48(47)$ & $70(50)$ & $182(46)$ & \\
\hline \multicolumn{6}{|l|}{ Surgical Procedure, number (\%) } \\
\hline Mastectomy & $66(44)$ & $50(49)$ & $65(46)$ & $181(46)$ & \multirow{3}{*}{$\begin{array}{l}P \leq 1 \\
\text { NS }\end{array}$} \\
\hline Lumpectomy & $67(44)$ & $42(41)$ & $60(42)$ & $168(42)$ & \\
\hline No surgery & $18(12)$ & $9(9)$ & $16(11)$ & $43(11)$ & \\
\hline \multicolumn{5}{|l|}{ Chemotherapy, number (\%) } & \multirow{3}{*}{$\begin{array}{l}P \leq 0.20 \\
\text { NS }\end{array}$} \\
\hline Yes & $22(14)$ & $12(12)$ & $11(8)$ & $45(12)$ & \\
\hline No & $129(85)$ & $89(88)$ & $130(92)$ & $348(88)$ & \\
\hline Radiation therapy, number (\%) & & & & & \\
\hline Yes & $47(31)$ & $21(21)$ & $30(21)$ & $98(25)$ & $\begin{array}{l}P \leq 0.10 \\
\text { NS }\end{array}$ \\
\hline No & $104(69)$ & $80(79)$ & $111(79)$ & $295(75)$ & \\
\hline
\end{tabular}


Table 1: Continued.

\begin{tabular}{|c|c|c|c|c|c|}
\hline \multirow{2}{*}{ Characteristic } & \multicolumn{3}{|c|}{ Age } & \multirow{2}{*}{ Total } & \multirow{2}{*}{$P$ Value } \\
\hline & $70-74$ & $75-79$ & $\geq 80$ & & \\
\hline Hormonal therapy, number (\%) & & & & & \multirow{3}{*}{$\begin{array}{l}P \leq 1 \\
\text { NS }\end{array}$} \\
\hline Yes & $58(39)$ & $38(38)$ & $52(37)$ & $148(38)$ & \\
\hline No & $93(61)$ & $63(62)$ & $89(63)$ & $245(62)$ & \\
\hline \multicolumn{5}{|l|}{ Had complete staging, number (\%) } & \multirow{3}{*}{$\begin{array}{l}P \leq 0.20 \\
\text { NS }\end{array}$} \\
\hline Yes & $115(76)$ & $73(72)$ & $93(66)$ & $281(71)$ & \\
\hline No & $36(24)$ & $28(28)$ & $48(34)$ & $112(28)$ & \\
\hline \multicolumn{5}{|l|}{$\begin{array}{l}\text { Alive at } 5 \text { years after initial contact, } \\
\text { number }(\%)\end{array}$} & \multirow{3}{*}{$\begin{array}{l}P \leq 0.001 \\
\quad \mathrm{~S}\end{array}$} \\
\hline Yes & $49(32)$ & $35(35)$ & $20(14)$ & $104(26)$ & \\
\hline No & $102(67)$ & $66(65)$ & $121(86)$ & $289(73)$ & \\
\hline
\end{tabular}

Abbreviation: NA: not applicable; NS: not significant; S: significant.

TABLE 2: Type of surgery and adjuvant treatment (1989-1999).

\begin{tabular}{|c|c|c|c|c|c|}
\hline \multirow{2}{*}{ Type } & \multicolumn{3}{|c|}{ Age } & \multirow{2}{*}{ Total } & \multirow{2}{*}{$P$ value } \\
\hline & $70-74$ & $75-79$ & $\geq 80$ & & \\
\hline Had mastectomy, number (\%) & $66(44)$ & $50(49)$ & $65(46)$ & \multirow[t]{6}{*}{$181(46)$} & \multirow{6}{*}{$\begin{array}{c}P \leq 0.20 \\
\mathrm{NS}\end{array}$} \\
\hline Alone & $28(42)$ & $29(58)$ & $37(57)$ & & \\
\hline With any adjuvant treatment & $38(58)$ & $21(42)$ & $28(33)$ & & \\
\hline With radiation therapy & $9(14)$ & $2(4)$ & $2(3)$ & & \\
\hline With chemotherapy & $7(11)$ & $4(8)$ & $3(5)$ & & \\
\hline With hormonal therapy & $22(33)$ & $15(30)$ & $23(35)$ & & \\
\hline Had lumpectomy, number (\%) & $67(44)$ & $42(41)$ & $60(42)$ & \multirow[t]{6}{*}{$168(42)$} & \multirow{6}{*}{$\begin{array}{c}P \leq 0.01 \\
\mathrm{~S}\end{array}$} \\
\hline Alone & $24(36)$ & $7(17)$ & $14(23)$ & & \\
\hline With any adjuvant treatment & $43(64)$ & $35(83)$ & $46(77)$ & & \\
\hline With radiation therapy & $22(33)$ & $12(29)$ & $15(25)$ & & \\
\hline With chemotherapy & $0(0)$ & $3(7)$ & $12(20)$ & & \\
\hline With hormonal therapy & $21(31)$ & $20(48)$ & $19(32)$ & & \\
\hline
\end{tabular}

Abbreviation: NA: not applicable; NS: not significant; S: significant.

TABLE 3: Indications for adjuvant therapy and rates of treatment (1989-1999).

\begin{tabular}{|c|c|c|c|c|c|}
\hline \multirow{2}{*}{ Indication } & \multicolumn{3}{|c|}{ Age } & \multirow{2}{*}{ Total } & \multirow{2}{*}{$P$ value } \\
\hline & $70-74$ & $75-79$ & $\geq 80$ & & \\
\hline Positive lymph nodes, number & 40 & 25 & 31 & 96 & NA \\
\hline \multicolumn{5}{|l|}{ Received chemotherapy, number (\%) } & \multirow{3}{*}{$\begin{array}{c}P \leq 1 \\
\text { NS }\end{array}$} \\
\hline Yes & $22(55)$ & $12(48)$ & $11(35)$ & $45(47)$ & \\
\hline No & $18(45)$ & $13(52)$ & $20(64)$ & $51(53)$ & \\
\hline Positive margins of resection, number & 47 & 27 & 44 & 113 & NA \\
\hline \multicolumn{5}{|l|}{ Received radiation therapy, number (\%) } & \multirow{3}{*}{$\begin{array}{c}P \leq 0.05 \\
\mathrm{~S}\end{array}$} \\
\hline Yes & $42(89)$ & $21(78)$ & $30(68)$ & $98(87)$ & \\
\hline No & $5(11)$ & $6(22)$ & $14(32)$ & $25(13)$ & \\
\hline Progesterone receptor positive, number (\%) & $63(42)$ & $32(32)$ & $45(32)$ & 140 & NA \\
\hline Estrogen receptor positive, number (\%) & $69(46)$ & $44(43)$ & $58(41)$ & 171 & NA \\
\hline \multicolumn{5}{|l|}{ Received hormonal therapy, number (\%) } & \multirow{3}{*}{$\begin{array}{c}P \leq 1 \\
\text { NS }\end{array}$} \\
\hline Yes & $58(84)$ & $38(86)$ & $52(90)$ & $148(86)$ & \\
\hline No & $11(16)$ & $6(14)$ & $6(10)$ & $23(14)$ & \\
\hline
\end{tabular}

Abbreviation: NA: not applicable; NS: not significant; S: significant. 
chemotherapy either with a single agent or multiple agents. About $55 \%$ of patients in the $70-74$ years age group received chemotherapy as opposed to only 35\% in those 80 years old and greater. However, this difference was not significant $(P<1)$. There were 113 patients with positive margins of resection. Of those, $87 \%$ received radiation therapy. However, there was a significant difference in the number of patients who received radiation therapy in the 70-74 compared to that in the $\geq 80$ age group $(P \leq 0.025)$. In patients with hormone receptor positive status, $84 \%$ received hormone therapy in the 70-74 age group and about $90 \%$ in the $\geq 80$ age group.

\section{Discussion}

Previous studies have suggested that age was the strongest predictor of lesser treatment $[3,4]$ and that was what we sought to validate in the study. Our data have shown that there are observable differences in the different parameters measured among the subgroups and that there was a trend for the older cohort to be undertreated compared to the younger cohorts, but most of these observations were not deemed statistically significant.

A notable difference was that of survival after five years of diagnosis. Significant differences were noted between the 80 and older age group and the 70-74 and 75-79 age groups. However, whether or not age alone in this case is the strongest predictor for survival cannot be fully determined. But besides age, perhaps the findings also imply that survival is impacted by other parameters besides the tumor and patient characteristics identified in the study and that perhaps functional status and comorbidities play a role. Previous studies in other cancer researches have shown that central to the decision making in the elderly is the concept of life expectancy $[15,16]$. It is true that breast cancer increases with age. At the same time, as the age increases, the risk of death from causes besides breast cancer also increases [17]. Then, there is variability within an age cohort, with frail 70 year olds and robust 80 year olds. It is, therefore, significant to consider the patient's functional status and comorbidities in determining maximum treatment benefits for patients. It has been shown, for example, in cancer patients that poor functional status correlates with worse outcomes regardless of the type of cancer [18]. In weighing the benefits and risks of treatment therefore, breast cancer-specific prognosis, nonbreast-cancer-specific prognosis, and treatment-related toxicities should be accounted for. The National Comprehensive Cancer Network [19] has recommended the inclusion of the use of a geriatric assessment tool in developing care plans for the elderly cancer patient. Whether the assumption therefore, that perhaps functional status and comorbidities have contributed largely to the difference in survival cannot be determined as information was not available in the tumor registry.

Surgery is still the mainstay of treatment for patients with early stage cancer. It has been shown that breast conservation surgery which involves lumpectomy with or without subsequent axillary dissection, followed by irradiation, has equal efficacy to more extensive surgical options such as mastectomy. However, current data suggests that elderly women are less likely to be offered breast conservation surgery than their younger counterparts (25\% versus 42\%) [20, 21]. Our study has shown that in this institution, mastectomy and lumpectomy were performed at almost the same frequency although adjuvant therapy was omitted in most cases.

Staging was done for majority of patients (71\%). There was no difference between age groups $(P<0.20)$ although younger patients were staged more than the 80 years and older cohort. Again, whether this was because of age alone cannot be determined.

Still regardless of age, infiltrating ductal carcinoma is the most common histologic subtype as demonstrated in our study as well. Older patients have also been noted to have a greater frequency of tumors with more indolent histologies and overall more favorable biologic tumor profile. Older women are likely to express estrogen and progesterone receptors, which improves prognosis. This also makes them candidates for adjuvant hormonal therapy [22, 23]. In our study, majority of the patients with positive hormone receptor status received hormonal therapy. As suggested by prior studies, treatments that offer less toxicity are offered to patients with advanced age. Hormonal therapy which carries less risks and toxicity compared to chemotherapy is more likely to be offered and given to elderly patients with breast cancer.

With regard to chemotherapy, cytotoxic drugs most commonly used in this setting like cyclophosphamide, methotrexate, and 5-fluorouracil represent the second line of systemic therapeutic agents available for women with breast cancer. There is paucity of data when it comes to women over the age of 70. In the Early Breast Cancer Trials Collaborative Group, it was shown that chemotherapy did not offer any advantage in survival for women over the age of 70 [24]. However, part of the limitation of this study was that there were very few cohorts over age 75 and that dosing was much less compared to the younger patient cohorts. Our study have shown that chemotherapy was not generally offered to our study cohort and although there was no statistical difference, there was note of a trend to give less chemotherapy as the patient gets older (see Table 3). This may stem from issues of toxicity of these agents and also by suggestions of less advantage as presented in previous trials.

Radiation therapy is well tolerated in the elderly. It decreases ipsilateral breast cancer recurrence after breast conservation surgery and chest wall recurrence after a mastectomy. Our study showed that in patients 80 years and older, radiation therapy was given less than that in the 70-74 year old cohort (see Table 1), which is reasonable given numerous data that merely show a decrease in local recurrence but ultimately had no effect on survival [25, 26]. A previous study by Fyles et al. [27] showed that despite reduced risk of local $(7.7$ to $0.6 \% P<0.001)$ and axillary $(2.5$ to $0.5 \% P<0.49)$ recurrence, there was no significant difference in survival. The study of Ragaz et al. [28] demonstrated the same trend of decrease in locoregional recurrence but no advantage in decreasing distant metastasis or improving survival. It may be reasonable, therefore, to 
offer radiation therapy to patients who may benefit most such as those with life expectancy greater than 5 years, those with large tumors, positive lymph nodes, or negative hormone receptors.

\section{Conclusions}

Treatment of breast cancer in the elderly patient in a community setting, which in this case is The Brooklyn Hospital Center, has shown that there is a trend to having undertreatment with advancing age. It was likewise demonstrated that despite similar patient and tumor characteristics, the fiveyear survival significantly differed among the different age cohorts. To validate whether this is due to age alone, data on comorbidities and the patients' functional status should also be determined. It would also be significant to determine whether the patients recorded as not having received therapy were actually offered but refused, or never offered because of various reasons at all, as that would demonstrate more clearly the treatment practices as it relates to age and other patient characteristics.

\section{Acknowledgments}

The authors are indebted to Dr. Kim I. de la Cruz, MD and Dr. Maxine Grace J. de la Cruz, MD, who are no longer in our institution, for their previous contributions to the data assembly and analysis and to Ms. Marva A. Shelton-Delapp, CTR for her contributions to the original data collection.

\section{References}

[1] C. E. Holmes and H. B. Muss, "Diagnosis and treatment of breast cancer in the elderly," Ca: A Cancer Journal for Clinicians, vol. 53, no. 4, pp. 227-244, 2003.

[2] Society AC, Breast Cancer Facts and Figures 2003, American Cancer Society, Atlanta, Ga, USA, 2003.

[3] C. Owusu, T. L. Lash, and R. A. Silliman, "Effect of undertreatment on the disparity in age-related breast cancer-specific survival among older women," Breast Cancer Research and Treatment, vol. 102, no. 2, pp. 227-236, 2007.

[4] C. Gajdos, P. I. Tartter, I. J. Bleiweiss, R. A. Lopchinsky, and J. L. Bernstein, "The consequence of undertreating breast cancer in the elderly," Journal of the American College of Surgeons, vol. 192, no. 6, pp. 698-707, 2001.

[5] K. Hancke, M. D. Denkinger, J. König et al., "Standard treatment of female patients with breast cancer decreases substantially for women aged 70 years and older: a German clinical cohort study," Annals of Oncology, vol. 21, no. 4, pp. 748-753, 2009.

[6] V. Velanovich, M. Gabel, E. M. Walker et al., "Causes for the undertreatment of elderly breast cancer patients: tailoring treatments to individual patients," Journal of the American College of Surgeons, vol. 194, no. 1, pp. 8-13, 2002.

[7] M. Tahir, T. Robinson, and A. Stotter, "How not to neglect the care of elderly breast cancer patients?" Breast, vol. 20, no. 4, pp. 293-296, 2011.

[8] C. Bouchardy, E. Rapiti, G. Fioretta et al., "Undertreatment strongly decreases prognosis of breast cancer in elderly women," Journal of Clinical Oncology, vol. 21, no. 19, pp. 35803587, 2003.
[9] K. J. Passage and N. J. McCarthy, "Critical review of the management of early-stage breast cancer in elderly women," Internal Medicine Journal, vol. 37, no. 3, pp. 181-189, 2007.

[10] D. A. Litvak and R. Arora, "Treatment of elderly breast cancer patients in a community hospital setting," Archives of Surgery, vol. 141, no. 10, pp. 985-990, 2006.

[11] J. H. Lewis, M. L. Kilgore, D. P. Goldman et al., "Participation of patients 65 years of age or older in cancer clinical trials," Journal of Clinical Oncology, vol. 21, no. 7, pp. 1383-1389, 2003.

[12] National Vital Statistics Reports, Centers for Disease Control and Prevention (CDC).

[13] US Preventive Services Task Force, Recommendations for Breast Cancer Screening.

[14] E. P. McCarthy, R. B. Burns, K. M. Freund et al., "Mammography use, breast cancer stage at diagnosis, and survival among older women," Journal of the American Geriatrics Society, vol. 48, no. 10, pp. 1226-1233, 2000.

[15] S. Eaker, P. W. Dickman, L. Bergkvist, and L. Holmberg, "Differences in management of older women influence breast cancer survival: results from a population-based database in Sweden," PLoS Medicine, vol. 3, no. 3, pp. 321-328, 2006.

[16] D. A. August, T. Rea, and V. K. Sondak, "Age-related differences in breast cancer treatment," Annals of Surgical Oncology, vol. 1, no. 1, pp. 45-52, 1994.

[17] N. Siegelmann-Danieli, V. Khandelwal, G. C. Wood et al., "Breast cancer in elderly women: outcome as affected by age, tumor features, comorbidities, and treatment approach," Clinical Breast Cancer, vol. 7, no. 1, pp. 59-66, 2006.

[18] S. M. Enger, S. T. Soe, D. S. M. Buist et al., "Breast cancer treatment of older women in integrated health care settings," Journal of Clinical Oncology, vol. 24, no. 27, pp. 4377-4383, 2006.

[19] National Comprehensive Cancer Network, "Practice Guidelines in Oncology—v.1.2007," Breast Cancer.

[20] H. J. Wanebo, B. Cole, M. Chung et al., "Is surgical management compromised in elderly patients with breast cancer?" Annals of Surgery, vol. 225, no. 5, pp. 579-589, 1997.

[21] B. J. Grube, N. M. Hansen, W. Ye, T. Herlong, and A. E. Giuliano, "Surgical management of breast cancer in the elderly patient," The American Journal of Surgery, vol. 182, no. 4, pp. 359-364, 2001.

[22] L. Balducci, M. Extermann, and I. Carreca, "Management of breast cancer in the older woman," Cancer Control, vol. 8, no. 5, pp. 431-441, 2001.

[23] L. Balducci, "Management of cancer in the elderly," Oncology, vol. 20, no. 2, pp. 135-143, 2006.

[24] A. Ring, M. Reed, R. Leonard et al., "The treatment of early breast cancer in women over the age of 70," British Journal of Cancer, vol. 105, no. 2, pp. 189-193, 2011.

[25] P. T. Truong, J. Lee, H. A. Kader, C. H. Speers, and I. A. Olivotto, "Locoregional recurrence risks in elderly breast cancer patients treated with mastectomy without adjuvant radiotherapy," European Journal of Cancer, vol. 41, no. 9, pp. 1267-1277, 2005.

[26] J. C. Lee, P. T. Truong, H. A. Kader, C. H. Speers, and I. A. Olivotto, "Postmastectomy radiotherapy reduces locoregional recurrence in elderly women with high-risk breast cancer," Clinical Oncology, vol. 17, no. 8, pp. 623-629, 2005.

[27] A. Fyles, L. Manchul, D. McCready, M. Trudeau, and S. Olsson, "Radiation for early breast cancer: is less more?" Discovery Medicine, vol. 5, no. 25, pp. 55-57, 2005. 
[28] J. Ragaz, I. A. Olivotto, J. J. Spinelli et al., "Locoregional radiation therapy in patients with high-risk breast cancer receiving adjuvant chemotherapy: 20-year results of the British Columbia randomized trial," Journal of the National Cancer Institute, vol. 97, no. 2, pp. 116-126, 2005. 


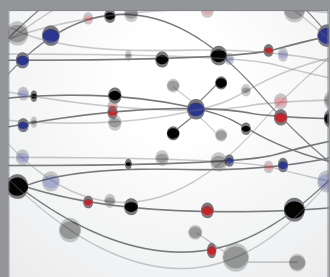

The Scientific World Journal
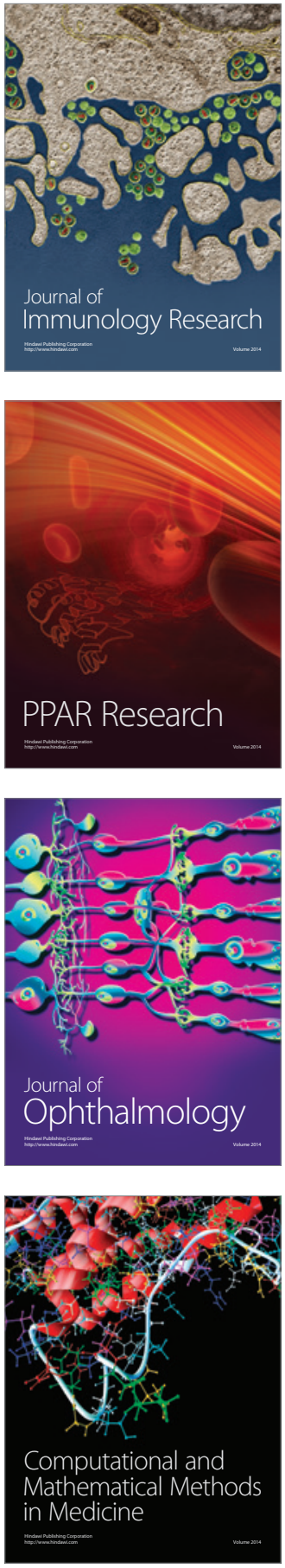

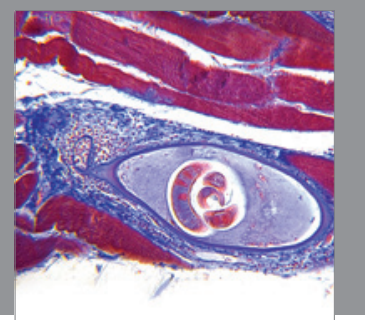

Gastroenterology

Research and Practice
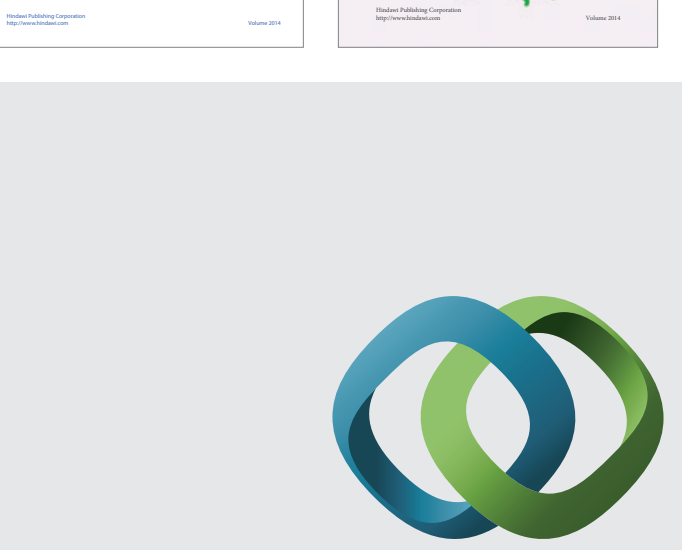

\section{Hindawi}

Submit your manuscripts at

http://www.hindawi.com
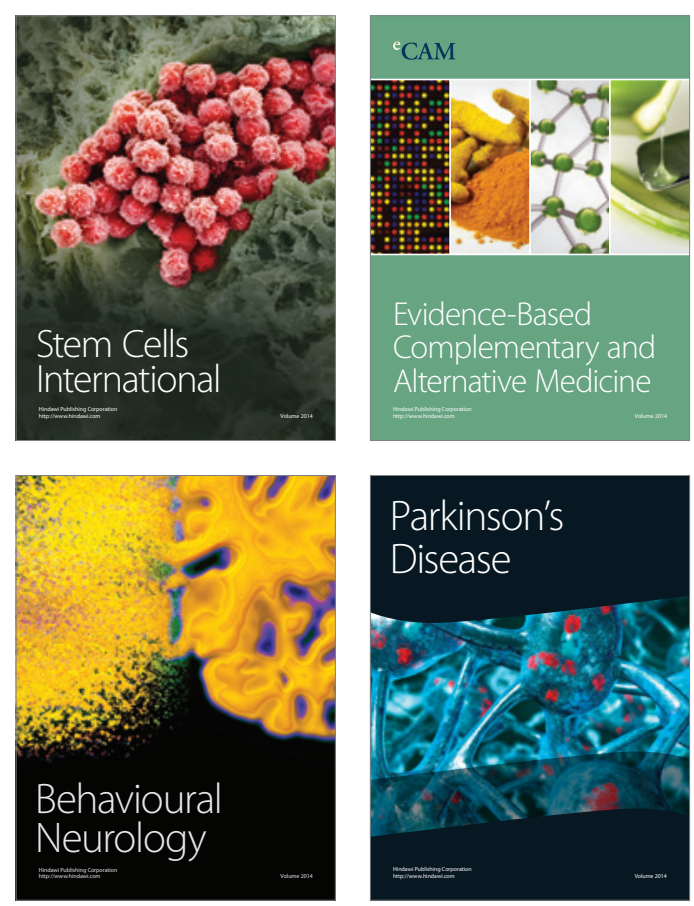

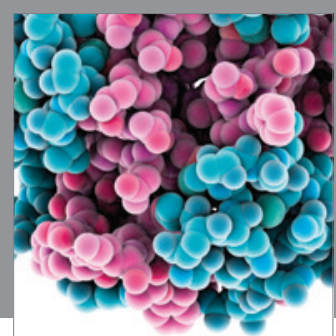

Journal of
Diabetes Research

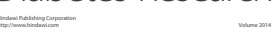

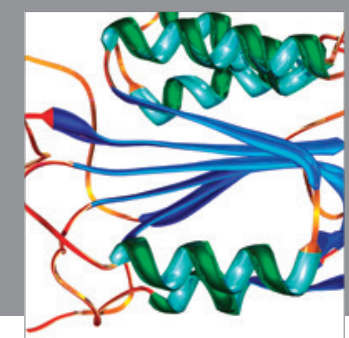

Disease Markers
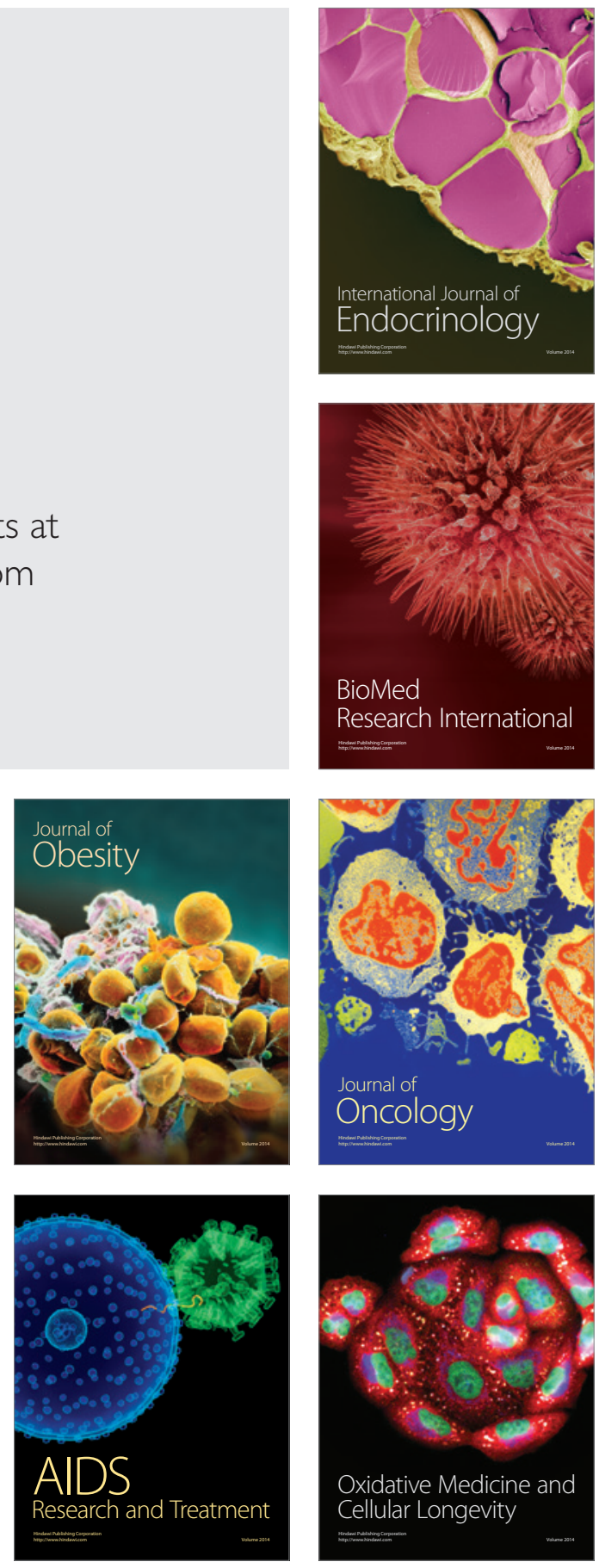